\title{
Analysis of Personal Freedom from the Perspective of Surrogacy
}

\author{
Gao $\mathrm{M}^{1, \text { a }}$ \\ Law School, Hunan University, Yuelu District, Changsha City, Hunan, China \\ a3583993926@qq.com
}

\begin{abstract}
The celebrity "Zheng Shuang" event in2021 has brought the topic of surrogacy to the attention of the general public once again. Not only is surrogacy a scientific medical technology but also it involves social ethics, economy, law, etc., but the surrogacy legislation still holds back. The reproductive right implied in the surrogacy is not only a basic human right but also falls within the category of personal freedom, so the surrogacy legislation is extremely urgent. Laws can be formulated by the National People's Congress and its standing committee to provide a legitimate guidance for the surrogacy, and meanwhile, the rights of surrogate child, surrogate mother and surrogacy client should be protected by the legal regulations.
\end{abstract}

Keywords: surrogacy legislation, reproductive right, personal freedom

\section{INTRODUCTION}

A child is of extraordinary significance to society, family or individuals. Reproduction is the major instinct of human beings, an important source of productivity in social development, and a way adopted by thousands and thousands of families to pursue the crystal of love. However, with the high-speed social development, the quantity of infertile people is also continuously increasing, and surrogacy, a technology assisting in the human reproduction (hereinafter abbreviated surrogacy), has become their route to realize the dream of bearing children. Nevertheless, China is considerably prudent in stipulating the surrogacy technology implementation, as the surrogacy involves various fields such as ethics, economics, politics and medicine. The surrogacy has not been given any legal certainty in China, yet, and the surrogacy is only explicitly forbidden by the department regulations enacted by the Ministry of Health in 2001 and 2003. But the surrogacy involves natural person's reproductive right, which belongs to the content of personal right, so whether the Ministry of Health is entitled to forbid or restrict such behavior related to "personal freedom" remains to be a problem. This research plans to analyze whether the reproductive right involved in the surrogacy belongs to the category of "personal freedom", summarize the reasons why the surrogacy needs to be forbidden in a limited way, and try to figure out whether the Ministry of Health has the right to formulate the related regulations to restrict "personal freedom".

\section{SURROGACY BELONGS TO THE CATEGORY OF PERSONAL FREEDOM}

\subsection{Surrogacy belongs to the category of personal freedom}

\subsubsection{Definition of personal freedom}

Personal freedom is the most important right in the modern human rights, and it can be traced back to Greater Charter of Liberties of UK. Afterwards, UK further developed the contents of personal freedom and constructed a relatively complete guarantee system for personal freedom by enacting Petition of Right and Writ of Habeas Corpus, etc. The civil right was not stipulated in the American Constitution in 1789, but "writ of habeas corpus" was specified in item 9 of Article 1, which took the Britain writ of habeas corpus was taken for reference. With the development of democratic system, the content of personal freedom protection is included into the constitutions of various countries in the modern times. In China, the personal freedom can be generalized in both broad sense and narrow sense ${ }^{[1]}$, where the personal freedom in broad sense refers to the protection of personal body and freedom of individual autonomy, including personal protection, and 
non-infringement upon residence, freedom of immigration and personal dignity, etc., and it is defined like this to expand the scope of personal freedom protection as far as possible. The personal freedom in narrow sense refers to individual right to control their own body and action. In other words, citizens shall not be arrested, taken into custody, interrogated or punished without the corresponding legal provisions. Meanwhile, the personal freedom can be divided into positive and negative aspects, where the former means that individuals have the freedom to manipulate themselves, which is the precondition for them to exercise or enjoy other basic rights, and the latter means restricting civil personal freedom, which is one of the main means endowed by the Constitution to the nation to punish offenders or those breaking the law, e.g. the punishment stipulated by the criminal law-completely deriving criminals of their physical freedom, and administrative detention stipulated by the administrative penalties law-depriving people violating the law of physical freedom in a short term. In addition, the expression of personal freedom can be divided into affirmative and negative expressions. The affirmative expression of personal freedom means directly listing the concrete contents of personal freedom, and the negative expression stipulates which behaviors shall not be done to the subject, and the latter is mostly adopted by constitutions of many countries. This means of expression indicates that the right is passive, and the legal protection is a reverse protection, namely the behaviors beyond those that shall not be done as legally stipulated are the contents of personal freedom, e.g., non-arrest, noninfringement upon personal freedom, etc.

\subsubsection{Surrogacy belongs to the category of personal freedom}

Throughout the history, the reproductive behavior usually occurs in the relations of human society, such as combination of man and woman, marriage and family, but with the development of science \& technology and ideology in human society, the reproductive behavior does not necessarily occur in the family relation or marital relation, such as the existence of homosexual marriage or homosexual partner. Before the emergence of artificial insemination and test-tube baby, child-bearing is completed only through the combination of man and women. However, the artificial insemination technology makes it possible for child-bearing to separate from such combination, and moreover, the technology of test-tube baby enables the fusion process of sperm and ovum to be completely divorced from the maternal womb ${ }^{[2]}$. This phenomenon is an inexorable outcome of scientific and technological development, so surrogacy has unavoidably become a reproductive means and a reproductive behavior. Hence, whether the reproductive right involved belongs to the category of personal freedom should be discussed in order to figure out whether the surrogacy belongs to the category of personal freedom.

Firstly, right can be divided into two types: obligatory right and actual right. According to a scholar ${ }^{[3]}$, the reproductive right is a moral right or human right, that is to say, it is an obligatory right. Meanwhile, there is a view that the reproductive right is a legal right of real existence, that is, right of personal liberty, specifically corresponding to right of personality and identity right. Some scholars think that the reproductive behavior, in nature, is related to personality interest but not to identity interest. This personality interest is a right that must be shared by each legal subject, being unrelated to whether such subject has a specific identity. However, some scholars believe that the reproductive right is an identity right generated based on spousal relationship and a part of spouse right, and the establishment of reproductive right is good for perfecting the legal conjugal relation in China ${ }^{[4]}$. The author thinks that the reproductive right is a personality right, an inherent right of legal subject with the personality interest being the object, aiming to maintain the independent personality of legal subject. According to the concept of personality right, the internal connotation of reproductive right can be generalized as follows: First, the reproductive right is the sole right of legal subject; second, the reproductive right is a necessary right guaranteeing the reproductive behavior of legal subject; third, the reproductive right takes the reproductive interest as the object.

Secondly, according to the contents concerning reproductive freedom ${ }^{[5]}$ in the French Basic Law, the right theory of "personalism" is adopted, and "personality" refers to all beings of a natural person in all fields of life. As man is rational living being with absolute will, so man must be of autonomous deciding power in his/her comprehensive field of life, which is the fundamental condition for an independent person to maintain his/her personality and dignity. Therefore, the right theory of "personalism" takes the human personality and dignity as the highest value, and the Fundamental Law aims at guaranteeing human dignity. Thanks to the Fundamental Law, man can realize the comprehensive development in all fields of life, that is, the free development of personality and dignity; self-determination is the core of free development of human personality and dignity, thus becoming the core connotation in the protection of human personality and dignity by the constitution. As the human basic need, the reproductive freedom is obviously indispensable for the free development of human personality and dignity, so the reproductive right is included into the scope of protection of self-determination right-personal freedom. The American guarantee mechanism for reproductive freedom is mainly manifested in a series of judgments made by the supreme federal court with 
respect to privacy right. For instance, the concept of reproductive right was initially proposed in American "Act of Compulsory Sterilization" in $1942{ }^{[6]}$, elevating the reproductive right to the height of "basic freedom of man" and overturning the Oklahoman law, which imposed the compulsory sterilization on habitual felonious criminals. Based on the generalized concept of "freedom" in in the due process of Article 5 in the US Constitution, the grand justice Harlan Fiske Stone firmly believed that compulsory sterilization was the infringement upon human basic freedom. In the US Constitution, "personal freedom" is taken as the core value. The privacy right is not only restricted to the protection of personal privacy, but it also highlights eliminating the government intervention to realize the individual self-selection and self-determination of their own fields of life, namely, "everybody has the spiritual manifestation of shaping their own life and becoming the rulers of their own life of their own accord". In China, some scholars believe that the most ideal scheme is to establish the basic human right and status of reproductive freedom and clarify its basic connotation and limiting criteria, but this does not mean that it is necessary to write the reproductive freedom in the constitution by means of modifying the constitution. Just like the constitutions of many countries in the world, the reproductive freedom has not become the basic right explicitly listed in the Constitution of China, but the guarantee of human right by the Constitution is not restricted to rights listed in the Constitution, and the equal respect and guarantee must be given to those human rights not listed. In western constitutions, the reproductive freedom ${ }^{[7]}$ implies the right and status, because this innate and self-evident natural law nature of this right has been widely accepted, and moreover, in practice, it is not extensively infringed upon by state power, so it does not need to be explicitly expressed by the text of constitution to reinforce the protection. However, in China, the serious deficiency exists in the guarantee of reproductive freedom at both normative level or fact level. Therefore, defining the basic human right nature of reproductive freedom and clarifying its guarantee mechanism by explaining and implementing the constitution will be of great realistic significance. As for the interpretation technique of constitution, "national respect and guarantee of human right" specified in the Constitution of China can be taken as the generalized human right guarantee clause, the connotation of human right embodied in it is then explained, and then the reproductive freedom is included into the scope of protection of the Constitution, thus becoming the fundamental right unlisted in the Constitution. Therefore, the author thinks that the emphasis of reproductive freedom, no matter included into the scope of guarantee of privacy right or self-determination right, lies in the high individual self-determination regarding the reproduction matter. In many international documents, the concrete matters of high self-determination have been clearly expressed as the freedom to choose to or not to bear child and decide the quantity of children and birth interval, which actually reserves a broad autonomous space for individual reproductive activity. Accordingly, personal freedom means the right of natural persons to dominate their own body by virtue of their freedom of will and reject others' illegal interference. According to the concept of personal freedom, it can be known that the reproductive freedom belongs to the category of freedom just like personal freedom. The reproductive right involved in the surrogacy falls into the category of personal freedom, namely, individual freedom to own and dominate their own body.

\subsection{The reasons why the surrogacy should be regulated in a limited way}

The law of a good democratic state should reflect the objective law. People can acquire the freedom only when handling affairs according to the law that truly reflect the objective laws. To study the relationship between freedom and restriction is not to restrict freedom but to guarantee and expand the freedom, just as Locke once said, "The purpose of law is not to abolish or restrict freedom but to protect and expand the freedom". The reproductive right involved in the surrogacy belongs to the category of personal freedom, but this freedom needs a limited regulation [8], specifically for the following reasons:

\subsubsection{Thought of original sin}

In the theological doctrine system of Western Christianity, it is thought that man is a sinful and egoistical being since the birth. The story between Eve and Adam told in the Bible has also proved "evil of human nature". Due to such original sin, man will boundlessly take advantage of freedom after owning it, so their desire will be boundlessly expanded, too, thus infringing upon the freedom of others. Therefore, the right restriction mechanism should be reasonably formulated, and the abuse of rights should be prevented so as to ensure other basic rights. The reproductive freedom, involved in the surrogacy, indeed belongs to the category of personal freedom, but such freedom is never boundless. According to the theory of "thought of original sin", men will infringe upon the freedom and rights of others by using this freedom during the implementation process of surrogacy. In the process of surrogacy, the surrogate mother will be restricted by many conditions of the surrogacy client due to the existence of surrogacy contract. During the child-bearing process, the reproductive risks may generate personal harm. Furthermore, the surrogacy client may choose to suspend the agreement out of her own interest during the surrogacy. Under this circumstance, the surrogate mother will be both 
physically and mentally harmed if induced abortion is done, and if the surrogate mother chooses to continue the child-bearing, it will be hard to protect the child's interests. Because of "original sin" of man, the surrogacy client will only consider her own interests during the surrogacy or child-bearing process ${ }^{[9]}$, so the reproductive freedom of surrogate mother will be unavoidably intervened by the intentional surrogacy client, and her basic rights and interests will be correspondingly infringed upon.

\subsubsection{Public interest}

With the development of modern democratic system especially following the Second World War, more people have been dedicated to profound reflection upon national public power representing the public interests, while protecting the civilian personal freedom and dignity as the core of basic right. When the public interest conflicts with private interests, the basic civilian personal freedom can be protected only through the rightful and reasonable legal proceedings, so the restriction on interest is necessary. The artificial insemination technology and test-tube baby technology, which have grown mature in recent years, have facilitated the surrogacy to gradually develop into a "black gray" industry [10], and "Guangzhou octuplet event", "Beijing illegal surrogacy case of Hong Kong Fuchen Group", "domestic first surrogacy-induced guardianship dispute", etc. have aroused intensive social attention. Recently, the transnational surrogacy event of Chinese celebrity-Zheng Shuang - has radically led to the nationwide attention and discussion about the surrogacy. The commercialized development of surrogacy includes womb renting, sperm and egg sale, exploitation behind these, and challenge to human ethical bottom line, and other social negative problems, all of which are challenging the public interests step by step. The surrogacy is similar to human organ sale to some extent. Although some people have the needs for surrogacy, the state cannot arbitrarily hold an open attitude towards this for protecting the public interest. The state should enact the corresponding law to regulate the surrogacy in order to avoid social disorder, and provide a correct guidance for the existing behaviors through normative document of law.

\subsubsection{Harm principle}

As once pointed out by Marx, the right to do any activity that does not harm others is freedom. John Mill thought that "freedom means doing some things that do not harm others and their interests, and any individual violating this shall undertake the responsibility and bear social or legal punishment. First, a scholar ${ }^{[11]}$ deems that the commercial surrogacy may involve child problems. The first is children trafficking. The behavior or transaction of any individual or team transferring children to another person for rewards or other remunerations is referred to as children trafficking. From the literary meaning, if the definitions of "transfer", "remuneration" and "consideration" involved in the commercial surrogacy are consistent with the definition of children trafficking, this may harm the legitimate rights and interests of surrogate children. The second is children growth. Separating children from their surrogate mothers is not beneficial to their development, thus violating their interests, including their physical, mental, social and emotional development. Meanwhile, it is difficult to identify the motherhood for infants. Whether the pregnant mother or biological mother is the real mother of the infant is also difficult to be legislatively confirmed, and moreover, this issue can easily trigger disputes. In judicial practice, it has already become a phenomenon in modern times that surrogate mothers are loath to part from the children they bear and give birth to. In addition, as some foreign countries allow the surrogacy, enabling some people to seek for surrogate mothers at abroad, which will lead to all kinds of problems, like disputes triggered over how to confirm the infant identity and define their registered permanent residence after the birth. This harms the legitimate rights and interests of infants.

Based on the above deduction of basic theories, the author thinks that the existence of surrogacy is based on the reproductive right of intentional spouses, and the forbiddance of surrogacy is a compulsory stipulation specific to women exploitation and children trafficking, etc. Therefore, the logical result is that the surrogacy should be correspondingly restricted due to the non-justice and illegitimacy behind it, that is, incomplete forbiddance of surrogacy. From the social practice of surrogacy, it is deemed that the exploitation is not the intrinsic attribute of surrogacy arrangement, but due to the close relation between surrogacy and human body, the surrogacy arrangement can more easily cause the exploitation of women and infringement upon their human rights in other forms by external subjects during the implementation process. For example, Indian women are exploited a lot in the surrogacy arrangement.

\section{CURRENT STATUS OF REGULATION ON SURROGACY}

\subsection{Surrogacy is not explicitly forbidden in the Law of the People's Republic of China on Population and Family Planning}

In 2015, Law of the People's Republic of China on Population and Family Planning was revised, and the provision forbidding the surrogacy was added to the draft amendment. As stipulated by Article V of the draft amendment, to implement the human assisted reproductive technology, medical institutions shall obtain the approval from the health administrative 
department of provincial people's government. Meanwhile, the sales of sperm, egg, zygote and embryo was forbidden, so was the surrogacy in any form. If this draft could be passed, it would mean that the surrogacy was formally forbidden from the legislative level in China. However, in the group review of Standing Committee of the National People's Congress on the draft amendment of Law of the People's Republic of China on Population and Family Planning, the participants in the review had a great divergence over the abovementioned Article V in the draft. By study, the Legal Committee decided to delete the provisions in Article V together with the associated article VI in the draft amendment, namely, "any surrogate behavior will be accordingly punished". According to some scholars, the reason why the provisions about forbiddance of surrogacy was deleted in Law of the People's Republic of China on Population and Family Planning was that China was intended to lift the restriction on surrogacy to cope with the social pressure brought by the ever-increasing infertile patients. According to another scholar ${ }^{[12]}$, the article of surrogacy forbiddance in the draft was deleted in the draft because surrogacy was a human assisted reproductive behavior that seriously violated the human nature, and therefore, the surrogacy should be legally forbidden. The author holds that the Article V (To implement the human assisted reproductive technology, medical institutions shall obtain the approval from the health administrative department of provincial people's government. Meanwhile, the sales of sperm, egg, zygote and embryo is forbidden, so is the surrogacy in any form) and Article VI (any surrogate behavior will be accordingly punished) were deleted in the draft amendment of Law of the People's Republic of China on Population and Family Planning in 2015 for the following reasons: First, the time was not right. The draft amendment of Law of the People's Republic of China on Population and Family Planning in 2015 mainly aimed to comprehensively implement the "double-child" policy as proposed on the Fifth Plenary Session of the $18^{\text {th }}$ CPC National Congress, this provision was not directly related to the comprehensive implementation of two-child policy, and some problems remained to be deeply studied and demonstrated; second, great disputes existed. A law is formulated usually to expressly stipulate the problem over which a consensus is reached, while any controversial problem may not be involved temporarily, which can not only improve the promulgation efficiency of law but also prevent controversial problems from being written into the law in haste, which will generate greater negative impacts; third, legislative technology problem. As an assisted reproductive mode that breaks the convention and challenges the traditional reproductive morals, the surrogacy has become a topic arousing fierce discussion in domestic and foreign medical communities, jurisprudential circles, ethical communities and academic circles of population and society since its birth, and the enormous conceptual conflict and ideological clash it triggers have never been ceased. In a word, that the provisions in Article $\mathrm{V}$ and Article VI over the surrogacy problem in the draft amendment of Law of the People's Republic of China on Population and Family Planning does not embody the legislative attitude of China towards the surrogacy, namely, forbidding or allowing.

\subsection{Surrogacy is expressly forbidden in the Regulations and Ethics Principles}

The existing regulations on the surrogacy in China is mainly embodied in two administrative regulations: The first is 2001 Regulations on Human Assisted Reproductive Technology (hereinafter abbreviated as the Regulations), stipulating in Item 2 of Article III that the transaction of gamete, zygote and embryo in any form is forbidden. Medical institutions and medical personnel shall not implement the surrogacy technology of any form. Any behavior violating this provision will be punished in accordance with Article XXII of the Regulations: "the health administrative department of provincial, autonomous region or municipality people's government gives a warning and imposes a penal sum below 30,000 yuan, along with the administrative sanction on the relevant person in charge. When the circumstances are so serious as to constitute a crime, the criminal sanction will be given according to law". The second is 2003 Ethics Principles of Human Assisted Reproductive Technology and Human Sperm Bank (hereinafter abbreviated as the Ethics Principles), which reiterated the forbiddance of surrogacy technology. The Ethics Principles confirms the seven basic principles regarding the management of human assisted reproductive technology and human sperm bank, where the specific provisions in multiple principles have embodied the attitude of forbidding the surrogacy. For example, it is stipulated in the principle of public welfare that "medical personnel must carry out the related activities in strict accordance with the articles in Law of the People's Republic of China on Population and Family Planning, and the human assisted reproductive technology shall not be implemented for couples and single women who do not conform to the provisions of Law of the People's Republic of China on Population and Family Planning. It is noteworthy that the decision-making body of both regulations is the Ministry of Health. From the above property analysis of reproductive freedom involved in the surrogacy, the surrogacy belongs to the category of personal freedom. However, the coercive measures and punishments about restricting civilian personal freedom as stipulated in Article VIII of the Legislation Law can only be fitted by law, while the specifications formulated by the Ministry of Health still belong to department regulations in nature, so is it entitled to regulate the surrogacy involving the personal freedom? According to the author, the coercive 
measures and punishments, which are of ordinary meaning, about restricting civilian personal freedom mean that civilian immunity from arrest, detention, etc., but this expression in general sense is only a negative expression of personal freedom. In consideration that the personal freedom is also affirmatively expressed, and these affirmative expressions are generally embodied in the department laws formulated by National People's Congress and its Standing Committee, for example, privacy right and right of reputation stipulated in the Civil Law both belong to affirmative expressions of personal freedom, and thus the protection of human rights and personal freedom stipulated in the Constitution has been refined and concretized through the department law-the Civil Law. Because both the Regulations and Ethics Principles belong to department regulations, the attitudes of forbidding or allowing the surrogacy held in the two department regulations are worthy of discussion.

\section{SUGGESTIONS FOR REGULATION ON THE SURROGACY}

First, by analyzing the property of surrogacy, the surrogacy should indeed be regulated by law. Marx once pointed out that "the activity that can be done by man is an activity harmless to others, and the boundary of this activity is legally stipulated, just as the boundary of a piece of land is decided by the landmark". The just law is a reflection upon the objective laws, legislators should image themselves as natural scientists, and recognize that they are not creating or inventing the law but just expressing it, and presenting the intrinsic rules into the conscious law. Freedom itself is a cognition of objective law and transforms the objective world based on this cognition, so of course, it is also restricted by the law. The advent of surrogacy is an inevitable result of the development of social science and technology. Nevertheless [13], the legal attitude towards the surrogacy shall not be absolute forbiddance, but should be limited permission by giving full play to the guiding role of law. Furthermore, the substantial law, a law reflecting objective laws, forms an intrinsic restriction on the freedom.

Second, the law regulating this behavior shall be the law stipulated by the Legislation Law and formulated by the National People's Congress and its Standing Committee. Because the content of reproductive freedom involved in the surrogacy falls into the category of personal freedom, the regulation on this behavior involves the restriction on civilian personal freedom. There are social needs for the surrogacy, and some needs are reasonable, such as the reproductive right of infertile couples, so a specialized assisted reproduction law should be formulated based on the comprehensive investigation and demonstration. Gradually realizing the legalization of surrogacy from the angle of perfecting the legislation is still a goal that should be pursued by the China's legislation about the surrogacy. However, attention should be paid to the gradual perfection during the realization of this goal, instead of totally repudiating the previous legislations. The surrogacy is blended with various legal issues, so it is a major obstacle in many legal fields. The surrogacy itself indicates that the transfer of any system in the legal system may impact other legal norms.

\section{CONCLUSION}

On the precondition of admitting that the surrogacy belongs to the category of personal freedom, the harms caused by the surrogacy can be effectively regulated and eliminated only through the reasonable legislation. Regulating the surrogacy by the legislation has become a goal of some countries and international communities. The concept of sustaining families through the reproduction is indestructible in China. The artificial assisted reproductive technology not only solves the fertility problem of infertile people ${ }^{[14]}$, but also provides a better means for homosexuals to complete the child-bearing process. In an era where the surrogacy is widely accepted and applied, we must affirm the welfare brought by the surrogacy to special groups. However, there is no clear attitude towards the surrogacy in China's legislation process. Hence, the author suggests perfecting the legal systems and clearly regulating the surrogacy through the legislation process, so as to promote its legalization and benefit many "unfortunate" families.

\section{REFERENCES}

[1] Jian M. (2011) Constitutionality analysis of restriction on personal freedom. Shandong Academy of Governance, 01:67-69.

[2] Xu Y H, Yang H Y. (2021) Demarcation route analysis of legitimate surrogacy types in China. China Health Law, 01:11-13.

[3] Gong P X. (1999) Theoretical Logic of Modernization of Legal System. China University of Political Science and Law Press, Beijing.

[4] Jiang Y. (2007) Introduction to Marriage and Family Law. Science Press, Beijing.

[5] Yu J. (2016). Protection and Regulation of Reproductive Freedom: Enlightening Significance of U. S. Constitution and German Basic Law for China. Journal of Wuhan University (philosophy \& social sciences edition), 05: 110-117.

[6] skinner v. oklahoma,316U.S.535.1942。

[7] Xu Z W. (2000). On Freedom, Decision-making Power, Fertility Power and Situation. Medicine \& 
Philosophy, 4: 45-47.

[8] Liu Y L. (2005) On Legal Restriction on Child-bearing Right. Journal of Gansu Political Science and Law Institute, 11:52-58.

[9] Zheng X Q. (2021) What legal risks are faced by the surrogacy? JKB, 07

[10] Xu W. (2019) Discrimination and classification: on the solution to the basic disputes over surrogacy events. Hebei Law Science, 11: 136:152.

[11] Yu T. (2016) Comparative Study of Surrogacy Laws in Different Countries. China University of
Political Science and Law Press, Beijing

[12] Liu C Q. (2021) Surrogacy legislation is extremely urgent. Faren Magazine, 02:60-70

[13] Zou L Q, Liu C. (1993) Reflects upon freedom and restriction from the angle of philosophy of law. The Jurist, 04:47-52.

[14] Tang J Q. (2019) Ethical considerations on legalization of non-commercial pregnancy-type surrogacy. Medicine \& Philosophy, 14: 38-42. 